\title{
Prevalence of symptoms and risk of sleep disordered breathing in Mumbai (India)
}

\section{Shailly Saxena, D Gothi, J M Joshi}

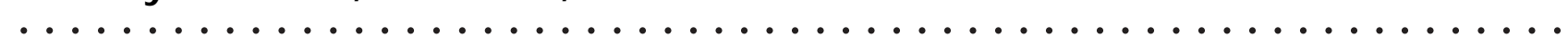

Indian J Sleep Med 2006;1.1, 27-31

See end of article for authors affiliations

Address for correspondence:

Dr. Shailly Saxena

Consultant Pulmonologist, O PD NO .:26, The Gujarat Research \& Medical Institute, Rajasthan Hospitals, Shahibaug, Ahmedabad380004 shaillysaxena@hotmail.com

\begin{abstract}
Study Objective: To estimate prevalence of sleep disordered breathing (SDB) in a questionnaire based survey in Mumbai (India).

Methods: The observational design of the study was on a cross-sectional basis conducted at various locations in the city of Mumbai, India. 20 patients of obstructive sleep apnoea (OSA) were selected randomly as index cases and their residential addresses were noted. From the neighborhood of each of the 20 index cases, a random sample of 20 households was selected providing a sample of $20 \times 20=400$ households. In each the selected households a well-structured questionnaire was canvassed. The information thus collected from the 400 sample households formed the basis of the present study. A total of 1188 sleep questionnaires were administered by a paramedical worker to individuals above 18 years of age and the responses regarding the occurrence of snoring, habitual during or non habitual, cessation of breathing during sleep (witnessed apneas), and daytime sleepiness as per the Epworth sleepiness scale were noted. Results: The information obtained from 1188 subjects - 667 males and 521 females, was tabulated and statistical analysis was carried out using SPSS software. Habitual snoring was observed in $6.4 \%$ of population. O ut of these habitual snorers, two cases had excessive daytime sleepiness and witnessed apneas. The prevalence SDB, after considering its risk factors i.e. habitual snoring, excessive daytime sleepiness and witnessed apneas was found to be $3.42 \%$ on the maximum side in the study population. Conclusion: $6.4 \%$ of adult Indian population suffers from snoring and prevalence of OSA on the maximum side in the study population is $3.42 \%$.
\end{abstract}

Keywords: O bstructive sleep apnoea, Sleep disordered breathing, Prevalence

\section{Introduction}

S leep disordered breathing (SD B) are disorders of breathing during sleep, the importance of which has been recognized over the last two decades'. Thecommonest disorders in thespectrum of SD B include snoring and obstructive sleep apnoea (OSA). OSA is characterized by repeated episodes of complete upper airway obstruction during sleep. The cardinal features include snoring, apneic spells and sleep fragmentation. Fatigue, morning headache, excessive daytime somnolence and loss of concentration, judgment and memory areother associated clinical features. ${ }^{2,3} \mathrm{H}$ abitual snoring is the most prominent manifestation related to obstructive sleep apnea syndrome (OSAS) and may cause hypoxemia and hypercapnia due to the partial obstruction of the upper airway during sleep. ${ }^{4}$ Various studies, 6,7 have reported community prevalence of habitual snoring in adults to be about $11-15 \%$. Between $30-50 \%$ of the adult habitual snorers ${ }^{6}$ are estimated to have the OSA, which is estimated to occur in $2-4 \%$ of general population. $6.7,8,9$

Abbreviations: sleep disordered breathing (SDB), obstructive sleep apnoea (OSA) excessive daytime sleepiness (EDS)

Indian Journal of Sleep M edicine (IJSM ), Vol. 1, N o. 1, 2006 
The cardinal symptom of obstructive sleep apnea is excessive daytime sleepiness. Excessive daytime sleepiness appears to result from sleep fragmentation related to recurrent central nervous system arousals in responseto disordered breathing events. ${ }^{10} \mathrm{O}$ f the relatively few population-based epidemiological studies designed primarily to investigate snoring and excessive daytime sleepiness (EDS), all have demonstrated positive associations ${ }^{11,12,13}$. C essation of breathing reported by the bed partner is usually a source of great anxiety because of fear that breathing may not resume and is a common symptom of O SA. ${ }^{14}$ Patients having persistent symptoms of snoring, observed apneic episodes during sleep and daytime sleepiness have been considered high risk for OSA. ${ }^{15}$

Although cases of OSA have been documented in India, its prevalence and the prevalence of snoring and sleep-breathing disturbances in the general population are not known. A recent study from India estimated the prevalence of sleep apnoea to be $7.5 \%^{11}$. This study, however, included only middle aged urban men, was not community based and may not be representative of the Indian population as far as the age-segment and socio economic status are concerned.

Thus, a population based cross-sectional study of the adult population aged 18 and above was conducted in M umbai to determine the prevalence of habitual snoring, EDS and sleep disordered breathing.

\section{Materials and Methods}

The observational design of the study was on crosssectional basis and was approved by the ethics committee of the B.Y.L. Nair Charitable Hospital, Mumbai.

\section{The Study Population}

The study was conducted at various locations in the city of M umbai, which consists of populations of diverse ethnic groups hailing from different parts of India. 20 cases diagnosed as having OSA in our institute were taken as index cases. From the neighborhood of each of the 20 index cases, a random sample of 20 households was selected providing a sample of $20 \times 20=400$ households. In each the selected households a wellstructured questionnaire was canvassed. The information thus collected from the 400 sample households formed the basis of the present study.

Theinstitute caters to patients from various economic strata in the society. This ensured a sample containing a mixture of individuals from different socio-economic groups. 1188 questionnaires were administered to individuals aged 18 years and above, and their responses noted. T he response rate was $100 \%$. H owever, a varying number of questions in the questionnaire were not answered by all the respondents.

\section{The Sleep Q uestionnaire}

A sleep questionnaire (table 1) was designed to elicit information by personally interviewing the subjects or their spouses/roommates about the occurrence of snoring, habitual or non habitual, defined as snoring $>3$ days/week and < 3 days/week, respectively. It also included questionsto gather theinformation on cessation of breathing during sleep (witnessed apneas), sleepiness during the day as per the Epworth sleepiness scale. The questionnaires were printed in three languages generally spoken in M umbai, namely, $\mathrm{M}$ arathi, $\mathrm{H}$ indi and English. Themedium of conversation with the subjects was chosen

Table 1: Questionnaire (Brief version)

- Addiction

- Medical $\mathrm{H}$ istory about $\mathrm{H}$ ypertension, D iabetes $M$ ellitus, Ischaemic H eart Disease and others

- Weight gain

- Time taken to fall asleep

- Waking up after falling asleep

- N umber of hours of sleep

- Snoring, intensity of snoring, habitual/ nonhabitual

- $\quad \mathrm{H}$ istory of Choking

- $\quad$ Need to go to toilet at night

- $\quad$ on- refreshing sleep

- Headache/dryness of mouth on waking

- Excessive leg movement during sleep

- Accidents while driving/ cooking

- Psychosocial problems/ personality change

- Sudden attack of muscle weakness

- Tongue bite, bruxism, panic attack, and somnambulism

- Question related to Epworth Sleepiness Score 
in which he/she felt most comfortable. The subjects were interviewed at their usual place of residence by trained investigators.

\section{Results}

The information obtained from 1188 subjects - 667 males and 521 females, was tabulated and statistical analysis carried out using SPSS software.

The distribution of self reported snoring (habitual) by age and sex is given in table 2 . The graph of age-

Table 2: N umber of $\mathrm{H}$ abitual Snorers

\begin{tabular}{|l|l|l|}
\hline $\begin{array}{l}\text { Age Range } \\
\text { (Years) }\end{array}$ & $\begin{array}{l}\text { M ales } \\
\text { (\% among males) }\end{array}$ & $\begin{array}{l}\text { Females } \\
\text { (\% among females) }\end{array}$ \\
\hline$<30$ & $7(14.29)$ & $1(3.33)$ \\
\hline $30-39$ & $7(14.29)$ & $9(30)$ \\
\hline $40-49$ & $17(34.7)$ & $12(40)$ \\
\hline $50-59$ & $17(34.7)$ & $6(20)$ \\
\hline$>60$ & $1(2.04)$ & $2(6.67)$ \\
\hline Total & $\mathbf{4 9}$ & $\mathbf{3 0}$ \\
\hline
\end{tabular}

specific prevalence of habitual snoring showed a peak at the age-group 40-59 years and a downward trend at later ages (Fig.:1) . 19 subjects - 8 males and 11 females, reported the excessive daytime somnolence. $\mathrm{H}$ abitual snoring was reported in 79 patients in which, $49(62 \%)$ were males and $30(38 \%)$ females indicating a prevalence of $6.64 \%$ in the study population. The triad of habitual snoring, excessive daytime somnolence and witnessed apnoeas was reported in only 2 cases corresponding to $0.16 \%$ of the total respondents of the present study and

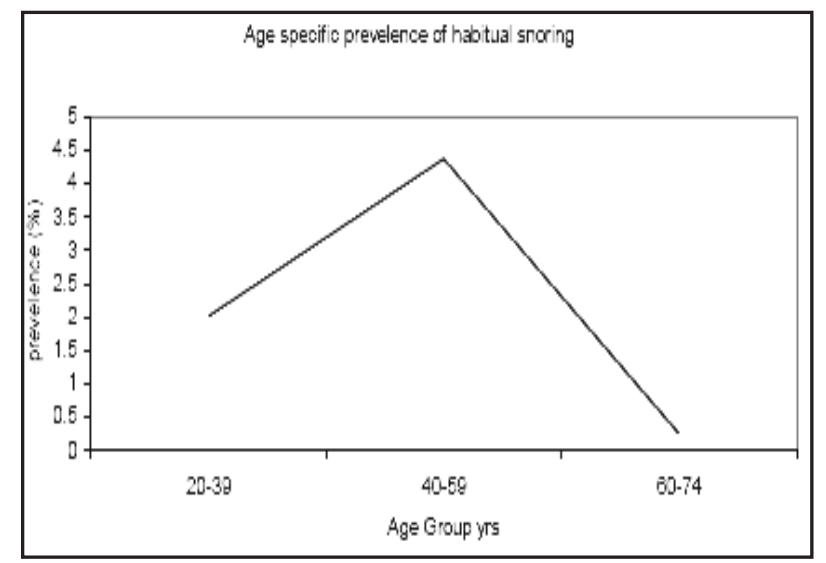

Fig. 1: Age specific prevalence of habitual snoring
$3 \%$ of the total habitual snorers.

The probability ' $p$ ' of having a positive case of SD $B$, out of the snorers is found 0.0253 and thus ' $q=(1-p)$ is 0.9747 . The variance ' $n p q$ ' of the estimate is 29.29 . The $95 \%$ confidence interval in which the estimate is likely to fall is given by 'mean $\pm 1.96 *$ S.D. The mean has been found to be 30.05 . Therefore, the confidence interval is $19.45-40.65$. The prevalence, calculated by dividing the lower and upper limits by total sample size (1188), from $1.64 \%$ to $3.42 \%$. The prevalence of sleep disordered breathing, after considering its risk factors, has thus been found to be $3.42 \%$ on the maximum side in the study population.

\section{Discussion}

All night polysomnographic data are generally adopted as the gold standard of defining SD B and OSA. Sleep symptom questionnaire data however, have been shown to provide a valid means of characterizing symptom distributions in population surveys of SD B/ OSA $12,13,16$, 17,18 and have been successfully employed in many community studies.

$\mathrm{H}$ abitual snorers often experience the effects of chronic sleep disruption, manifesting as excessive daytime somnolence, automatic behavior and cognitive and affective impairment. 0 ur study showed a frequency of habitual snoring in the adult representative population of I ndia to be $6.64 \%$. A study conducted in Singapore ${ }^{19}$ showed the prevalence to be $6.8 \%$ with the Chinese having the lowest prevalence (6.3\%) and Indians having the highest (11\%). The varied prevalence of sleep disordered breathing (SD B) in different studies $19,20,21$ may also be due to differences in population and to the methodological difficulties in characterizing these syndromes in large populations ${ }^{22}$. Also, the validity of responses from a questionnaire interview is an important consideration in evaluating estimates of prevalence of SD B in a population. Thus, in our study a trained paramedical worker was employed to perform the task. Similar to study in other population habitual snoring was seen more commonly in malesthan in females. Recent studies $12,13,16,17,18$ have supported the validity of sleep symptom questionnaires, with sleep apnoeas being well predicted by snoring and roommate observed symptoms of apnoea during sleep. People with snoring, excessive daytime somnolence, and nocturnal breath cessation are very likely to have sleep apnoea ${ }^{23,24}$. In the present study,

Indian Journal of Sleep M edicine (IJSM ), Vol. 1, N o. 1, 2006 
therefore, the syndrome of "sleep disordered breathing $(S D B)$ " has been defined by the triad of habitual snoring, witnessed apnoeas and excessive daytime somnolence (ED S score >9), which has been found to correlate highly with the severity of SDB ${ }^{25}$. Strollo and Rogers ${ }^{26}$ have also emphasized on the criteria of snoring with excessive daytime sleepiness and/or partner reports for cessation of breathing. $\mathrm{H}$ abitual snoring excessive daytime somnolence and witnessed apnoeas were reported in only two cases implying a prevalence rate of $0.16 \%$ in the entire sampleand a rate of $3.0 \%$ among the total habitual snorers. The upper limit of the prevalence of SD B, considering the risk factors for the same, has been found to be $3.42 \%$ of the population surveyed. Thus, estimated prevalence in Indian population is between $1.64 \%$ to $3.42 \%$. E pidemiological study from other countries have also estimated that $1-5 \%$ of adult men from normal communities have the "sleep apnoea syndrome" (objectivesleeping respiratory disturbance associated with daytime sleepiness) ${ }^{27}$.

The upper limit of the prevalence of risk factors of SD B in thestudy population has been observed as $3.42 \%$. Thissuggests that in India, up to about 34 million people may be suffering from sleep apnoea syndrome, which, if diagnosed and treated appropriately, could be relived of disabling symptoms related to these disorders.

\section{Acknowledgement}

This study was possible with a research grant from the Research society of the BYL N air hospital and Life Line, India. We also wish to thank M r. Santosh Juguste for his help in data collection.

\section{Authors' affiliations}

Shailly Saxena, Consultant Pulmonologist, The Gujarat Research \& Medical Institute, Rajasthan Hospitals, Shahibaug, Ahmedabad-380004

D Gothi \& J M J oshi, Department of Respiratory Medicine, T. N. Medical College, BYL Nair Hospital Mumbai 400008

\section{References}

1. Partinen M, Guilleminault C. Daytime sleepiness and vascular morbidity at seven year follow up in obstructive sleep apnea patients. Chest 1990; 97 (1): 27-32.

2. Whyte KF, Allen MB, Jeffery AA, Gould GA, Douglas NJ. Clinical features of the sleep apnea/hypopnea syndrome. Q J Med 1989; 72: 659-66.

Indian Journal of Sleep M edicine (IJSM ), Vol. 1, N o. 1, 2006
3. Obstructive sleep apnea syndrome.In: American Sleep Disorders Association, eds. The International Classification of Sleep Disorders, Revised: Diagnostic and Coding Manual. Rochester, MN, American Sleep Disorders Association, 1997; pp. 52-58

4. Shin C, Joo S, Kim J, Kim T. Prevalence and correlates of habitual snoring in high school students. Chest 2003 Nov; 124(5):1709-15

5. Fitzpatrick MF, Martin K, Fossey E, Shapiro CM, Elton RA, Douglas NJ. Snoring, asthma, and sleep disturbance in Britain: a community-based survey. Eur Respir J 1993; 6: 531-535

6. Cirignotta F, D'Allesandro R, Partinen M, et al.Prevalence of every night snoring and obstructive sleep apnoea among 30-69 year old men in Bologna, Italy. Acta Neurol Scand 1989; 79: 366-372

7. Lavie P. Incidence of sleep apnea in a presumably healthy working population: a significant relationship with excessive daytime sleepiness. Sleep 1983; 6: 312-318

8. Gislason T, Almqvist M, Ericksson G, Taube A, Boman G Prevalence of sleep apnea syndrome in Swedish men: an epidemiological study. J Clin Epidemiol 1988; 1: 571-576

9. Olson LG, King MT, Hensley MJ, Saunders N A. A community study of snoring and sleep disordered breathing.Prevalence. Am J Respir Crit Care Med 1995; 152: 711-716

10. Caples SM, Gami AS, Somers VK. O bstructive Sleep Apnea. Annals of Internal Medicine 2005; 142 (3):187-197

11. Udwadia ZF, Doshi AV, Lonkar SG, Singh CI. Prevalence of sleep-disordered breathing and sleep apnea in middle-aged urban Indian men. Am J Respir Crit Care Med. 2004 Jan 15;169(2):168-73. Epub 2003 Nov 06

12. Haraldsson PO, Carenfelt C, Tingvall C.Sleep apnea syndrome symptoms and automobile driving in general population. J Clin Epidemiol 1992; 45: 821-825.

13. Flemons Ww, Whitelaw WA, Brant R, Remmers JE. Liklehood ratios for sleep apnea clinical prediction rule. Am J Respir Care Med 1994; 150: 1279-1285.

14. Attarian HP, Sabri AN. When to suspect obstructive sleep apnea syndrome.Symptoms may be subtle, but treatment is straightforward. Postgrad Med 2002;111(3):70-6

15. Netzer NC, Stoohs RA, Netzer CM, Clark K, Strohl KP. Using the Berlin Questionnaire to identify patients at risk for the sleep apnea syndrome. Ann Intern Med. 1999;131:485-91

16. Olson LG, King MT, Hensley MJ, Saunders NA. A community study of snoring and sleep disordered breathing. Symptoms. Am J Respir Crit Care Med 1995; 152: 707-710.

17. Hoffstein V, Szalai JP.Predictive value of clinical features in diagnosing sleep apnea. Sleep 1993; 16: 118-122.

18. Kump K, Whalen C, Tishler PV. et al. Assessment of the validity and utility of sleep-symptom questionnaire. Am J Respir Care Med 1994; 150: 735-741

19. Ng TP, Seow A, Tan WC. Prevalence of snoring and sleep related- breathing disorders in Chinese, Malay and Indian adults in Singapore. Eur Respir J 1998; 12:198-202. 
20. Young T, Palta M, Dempsey J, Skatrud J, Weber S, Badr S. The occurrence of sleep disordered breathing among middle-aged adults. N Engl J Med 1993; 328:1230-5

21. Mary SM, Lam B, Lauder IJ, Tsang KWT, Chung K, Mok Y, Lam W. A community study of Sleep Disordered Breathing in Middle-aged Chinese Men in Hong Kong. Chest 2001; 119(1): 62-69.

22. Lindberg E, Gislason T. Clinical Review Article: Epidemiology of sleep-related obstructive breathing. Sleep Med Rev 2000;4(5): 411-33

23. Phillips B, Cook Y, Schmitt F, Berry D. Sleep Apnea:prevalence of risk factors in a general population.
South Med J. 1989 Sep; 82(9): 1092-2

24. Haqqee R, Hussain S.F., Mujib M, Ahmad H.R. A hospital based preliminary report on Sleep disordered breathing in Pakistani popultion. J Ayub Med Coll Abbottabad.2002 JulSep;14(3):2-4.

25. Johns MW. Sleepiness in different situations measured by the Epworth Sleepiness Scale. Sleep 1994; 17(8): 703-10

26. Strollo P. J., Rogers R.M. O bstructive sleep apnea. N Engl J Med 1996; 334: 99-104.

27. Davies Robert J O, Stradling John R. The epidemiology of sleep apnoea. Thorax 1996; 51:(Suppl 2): 565-570. 